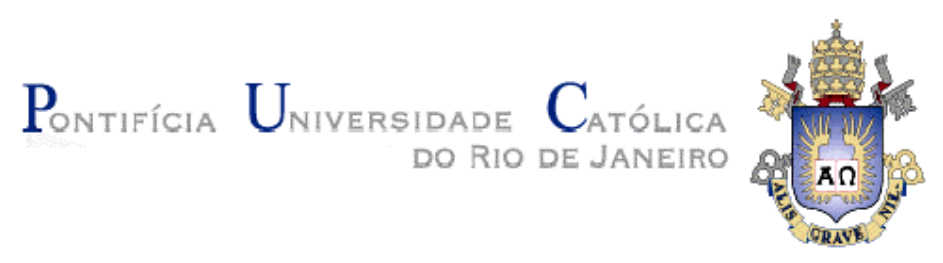

Alice Pereira Xavier

\title{
O Habitus Escolar na Construção da Qualidade do Ensino
}

\section{Tese de Doutorado}

Tese apresentada ao Programa de PósGraduação em Educação do Departamento de Educação da PUC-Rio como parte dos requisitos parciais para obtenção do título de Doutor em Educação.

Orientador: Prof ${ }^{a}$ Zaia Brandão 
Alice Pereira Xavier

\section{O Habitus Escolar na Construção da Qualidade do Ensino}

Tese apresentada como requisito parcial para obtenção do título de Doutor pelo Programa de Pós-Graduação em Educação do Departamento de Educação do Centro de Teologia e Ciências Humanas da PUC-Rio. Aprovada pela Comissão Examinadora abaixo assinada.

Prof ${ }^{a}$ Zaia Brandão

Orientadora

Departamento de Educação - PUC-Rio

Prof ${ }^{a}$ Alicia Maria Catalano de Bonamino Departamento de Educação - PUC-Rio

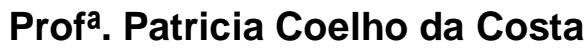
Departamento de Educação - PUC-Rio

Prof $^{\mathrm{a}}$ Hustana Maria Vargas

UFF

Prof. Tânia de Freitas Resende

UFMG

Prof ${ }^{a}$ Denise Portinari

Coordenadora Setorial do Centro de

Teologia e Ciências Humanas

Rio de Janeiro, 24 de abril de 2013. 
Todos os direitos reservados. É proibida a reprodução total ou parcial do trabalho sem autorização da universidade, da autora e do orientador.

\section{Alice Pereira Xavier}

Graduou-se em Pedagogia pela Universidade Federal do Rio de Janeiro (2005), é Mestre em Educação Brasileira (2009), pela PUC-Rio e pesquisadora associada ao grupo de Pesquisas em Sociologia da Educação, desde 2007. Participou de diferentes projetos de pesquisa, atuando nos seguintes temas: juventude, práticas pedagógicas, habitus escolar e qualidade do ensino

Ficha Catalográfica

Xavier, Alice Pereira

O Habitus escolar na construção da qualidade do ensino / Alice Pereira Xavier ; orientadora: Zaia Brandão . - 2013. 293 f. ; $30 \mathrm{~cm}$

Tese (doutorado)-Pontifícia Universidade Católica do Rio de Janeiro, Departamento de Educação, 2013. Inclui bibliografia

1. Educação - Teses. 2. Habitus escolar. 3. Disposições escolares. 4. Qualidade do ensino. 5. Escolas de prestígio. 6. Ensino público. 7. Ensino privado. I. Brandão, Zaia. II. Pontifícia Universidade Católica do Rio de Janeiro. Departamento de Educação. III. Título.

CDD: 370 
À Zaia Brandão, mestre instigante, que me ensinou o ofício da pesquisa. Ao Fernando Lage, amor e melhor amigo, que acreditou na concretização deste momento, muito antes dele acontecer. 


\section{Agradecimentos}

Na certeza de que não fazemos nada sozinhos, o meu reconhecimento e gratidão aos que fizeram parte do meu caminho.

À consciência de que algo maior existe; na busca pelo conhecimento, a presença de Deus deu maior sentido a este trabalho.

Aos meus pais, Jairo e Elaine e às minhas irmãs, Elisa e Cecilia, que compreensivos com as minhas ausências, sempre estimularam e apoiaram, mesmo no silêncio, a escolha em me dedicar a este trabalho.

À minha avó Ziette Lemos Pereira (in memoriam), professora admirável, que sempre me incitou a aprender.

À família que ganhei: Inês, Carlos, Bianca, Carine, Venceslau e os pequenos amados, Gabriel e Mariah, pelo apoio e incentivo.

À Maria Luiza Canedo, pela amizade e companheirismo incansáveis nestes quatro anos, todo meu carinho.

À Marcela e Hugo Mello Bento, casal amigo e presente nos momentos que mais precisei.

Aos professores, pais e alunos de escolas públicas e privadas, que tanto contribuíram com esta pesquisa.

Aos colegas da turma de doutorado (2009), em especial à Cecilia Lima e Luciana Cardoso, com a certeza de que conquistei amigos para toda a vida.

Às professoras que participaram das bancas de qualificação, Isabel Lelis, Hustana Vargas, Alicia Bonamino e Tânia Resende, pelo cuidado em avaliar este trabalho e pelas valorosas contribuições.

À Fernanda Braga, por sua revisão cuidadosa e ajuda prestimosa na formatação e organização desta tese.

Aos professores do Programa de Pós-Graduação em Educação da PUC-Rio, pelos ensinamentos valiosos que recebi para a profissão docente e pelo encorajamento à pesquisa.

Aos professores da comissão examinadora.

Ao CNPq e à PUC-Rio, pelo apoio financeiro. 


\section{Resumo}

Xavier, Alice Pereira; Brandão, Zaia. O habitus escolar na construção da qualidade do ensino. Rio de Janeiro, 2013. 293p. Tese de doutorado Departamento de Educação, Pontifícia Universidade Católica do Rio de Janeiro.

Este trabalho surge no contexto das pesquisas desenvolvidas no Grupo de Pesquisas em Sociologia da Educação - SOCED, especialmente do conjunto de informações reunidas sobre escolas públicas e privadas reconhecidas pela qualidade do ensino, na cidade do Rio de Janeiro. O principal aporte teórico e metodológico desta pesquisa foi baseado na obra de Pierre Bourdieu, especialmente voltada para os conceitos de habitus e homologia, e seus desdobramentos nas investigações sobre qualidade do ensino, sucesso e fracasso escolar, que encontram suporte nos conceitos de capital cultural, linguístico e simbólico, definidos pelo autor. Nesta perspectiva, importou-nos caracterizar e entender os processos de constituição dos habitus escolares, focalizando as práticas pedagógicas e familiares que sustentam parte do prestígio destas escolas. Propusemo-nos a investigar comose constroem as disposições, habilidades e valores, que estruturam o habitus escolar, sob a orientação de questões, tais como: Quais são as características das práticas educativas de sucesso nas escolas de prestígio e nas famílias? O que sabemos sobre as relações dos alunos com a escola ou sobre o seu cotidiano com os estudos? A investigação nos setores público e privado oportunizou diferenciar a realidade destas escolas, ultrapassando algumas percepções sustentadas pelo senso comum a respeito dos processos pedagógicos experimentados nestes contextos, bem como sobre as famílias atendidas nestas instituições. O levantamento estatístico e a análise do survey aplicado em 2009 a pais, alunos e professores nos ofereceram pistas instigantes para a sequência da investigação nas escolas nos anos seguintes (2010-2011), que aconteceu através de entrevistas com pais, alunos, diretores e coordenadores pedagógicos e a partir da observação dos espaços e eventos escolares. Por meio da investigação em uma perspectiva macro micro, foi possível realizar uma tipificação dos habitus escolares, caracterizando diferentes conjuntos de disposições acadêmicas e habilidades estudantis, desenvolvidas em diferentes instâncias de socialização, subsumidas nos contextos familiares e escolares, que sustentam a qualidade de ensino reconhecida destas escolas.

\section{Palavras-chave:}

Habitus escolar; Disposições escolares; Qualidade do ensino; Escolas de prestígio; Ensino público; Ensino privado. 


\section{Abstract}

Xavier, Alice Pereira; Brandão, Zaia. (Advisor).The habitus in the construction of educational quality. Rio de Janeiro, 2013. 293p. Thesis Departamento de Educação, Pontifícia Universidade Católica do Rio de Janeiro.

This work appears in the context of the research developed in Group Research in Sociology of Education - SOCED, especially the set of information gathered about public and private schools recognized by the quality of education in the city of Rio de Janeiro. The main theoretical and methodological framework was based on the work of Pierre Bourdieu, especially focused on the concepts of habitus and homology, and its developments in research on teaching quality, school success and failure, supported in the concepts of cultural capital, linguistic capital and symbolic capital, defined by the author. In this perspective, it mattered characterize and understand the formation of habitus involved in academic skills, focusing on pedagogical practices that sustain family and part of prestigious of these schools. We set out to investigate how is constructing the rules, skills and values that structure these habitus, under the guidance of questions such as: What are the characteristics of successful educational practices in prestigious schools and families? What we know about the relationships of students with school or about their daily lives with the studies? The investigation in the public and private sectors make possible to differentiate the reality of these schools, overcoming perceptions held by some common sense about the pedagogical processes experienced in these settings, as well as the families involved. The statistical analysis of the survey applied in 2009 to parents students and teachers offered us instigating clues to the continue of research in schools in the following years (2010-2011), which happened through interviews with parents, students, principals and coordinators and the observation of the spaces and school events. The micro macro research perspective it made possible to typify habitus, featuring different sets of rules and academic skills developed in different instances of socialization, subsumed in the family and school contexts, which sustain the quality of these recognized schools.

\section{Key-words:}

Habitus; Academic skills and dispositions; Quality of education; Prestigious school; Public education; Private education. 


\section{Sumário}

1. Introdução: produção da qualidade de ensino e formação de

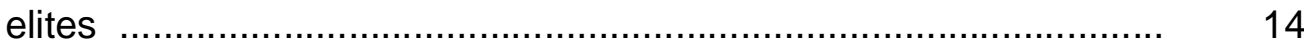

2. O conceito de habitus .................................................... 18

2.1. Uma relação estatística significativa? .................................... 23

2.2. Habitus e campo - jogo e sentido do jogo ............................ 25

3. Survey SOCED: Perfis dos alunos das escolas de qualidade ..... 27

3.1. O aluno: Agente mediador na constituição do habitus escolar . 38

3.2. Lançando um novo olhar: O trabalho de campo nas escolas ... 43

4. Estruturas organizacionais na escola pública e na escola

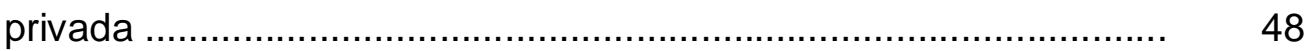

4.1. As escolas e seus agentes na formação do habitus escolar .... 59

4.2. A coordenação pedagógica nas escolas de qualidade ............. 66

4.2.1. A coordenação pedagógica na escola pública ....................... 69

4.2.2. A coordenação pedagógica na escola privada .................... 78

4.3. Que indivíduos as escolas fabricam ................................... 87

5. As famílias na construção do habitus escolar ........................... 92

5.1. Famílias na escola privada ................................................ 103

5.2. Mães na escola pública .................................................... 122

5.3. Habitus e disposições: famílias e escolas em colaboração ...... 142 
6. Uma abordagem exploratória sobre as disposições - habitus escolares

6.1. Alunos: adolescentes na escola pública e na escola privada ... 151

6.2. As entrevistas com os alunos da escola privada .................... 157

6.2.1. Rotinas ................................................................... 157

6.2.2. Comportamento acadêmico na sala de aula e na escola ...... 172

6.2.3. Expectativas de futuro ...................................................... 180

6.2.4. Impressões sobre a vida escolar ...................................... 184

6.2.5. O habitus escolar na instituição privada: a força do capital cultural e econômico ............................................................. 200

6.3. As entrevistas com os alunos da escola pública ..................... 207

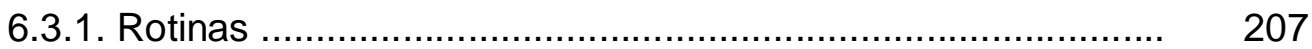

6.3.2. Comportamento acadêmico na sala de aula e na escola ...... 221

6.3.3. Expectativas de futuro ....................................................... 226

6.3.4. Impressões sobre a vida escolar ........................................ 229

6.3.5. O habitus escolar na instituição pública: herança escassa e esforço de reconversão ......................................................... 241

7. Considerações Finais: Tipos de Habitus Escolar ........................ 249

8. Referências Bibliográficas ……………………………........ 254

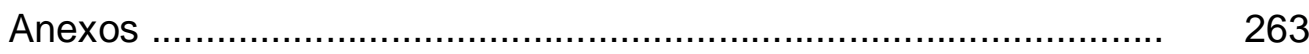




\section{Lista de Figuras}

Figura 1 - O habitus em Bourdieu - aproximação de um conceito . 20

Figura 2 - O cruzamento das disposições ...................................... 22

Figura 3 - Disposições escolares na escola privada ..................... 203

Figura 4 - Disposições escolares na escola pública ......................... 243

\section{Lista de Quadros}

Quadro 1 - Alunos e pais participantes do survey nas escolas públicas e privadas ................................................................ 28

Quadro 2 - Índice socioeconômico por rede escolar ....................... $\quad 29$

Quadro 3 - Índices socioeconômicos por escola ............................. $\quad 30$

Quadro 4 - Comparação com outras escolas - alunos .................. 31

Quadro 5 - Perspectiva de futuro dos alunos - estudos e trabalho 31

Quadro 6 - Perspectiva de futuro dos alunos - tipo de escola ........ 32

Quadro 7 - Uso do tempo dos alunos - Assistir TV ....................... 33

Quadro 8 - Uso do tempo dos alunos - Tarefas domésticas .......... 33

Quadro 9 - Uso do tempo dos alunos - Internet ............................. $\quad 34$

Quadro 10 - Uso do tempo dos alunos - estudar e fazer dever de

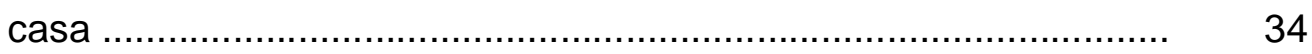

Quadro 11 - Frequência do estudo em casa - Pais ....................... 36

Quadro 12 - Verificar as tarefas escolares - Pais ......................... $\quad 36$

Quadro 13 - Ajudar nas tarefas escolares - Pais ........................... 37

Quadro 14 - Série de ingresso na escola ...................................... $\quad 39$

Quadro 15 - Senso de pertencimento - fazer amigos .................... $\quad 40$

Quadro 16: Senso de pertencimento - sentir-se entediado ............. $\quad 40$

Quadro 17 - Relação com os agentes escolares - colegas ............. 41

Quadro 18 - Relação com os agentes escolares - professores ...... 41

Quadro 19 - Classificação das regras de convivência da escola ..... 41 
Quadro 20 - Respeito às regras de convivência durante as aulas ..

Quadro 21 - Clima acadêmico - prestar atenção ao que o professor fala ................................................................ 42

Quadro 22 - Clima acadêmico - pedir ajuda ao professor ............... 42

Quadro 23 - Sistematização das observações de campo na escola privada

Quadro 24 - Sistematização das observações de campo na escola pública 50

Quadro 25 - Alunos matriculados na escola pública três ................. 61

Quadro 26 - Alunos matriculados na escola privada sete ............... 61

Quadro 27 - Série de ingresso dos alunos do nono ano nas escolas públicas

62

Quadro 28 - Série de ingresso dos alunos do nono ano nas escolas privadas

62

Quadro 29 - Exemplo de carga horária semanal na escola pública $\quad 64$

Quadro 30 - Exemplo de carga horária semana na escola privada .

Quadro 31 - Agentes de apoio pedagógico entrevistados na escola privada

Quadro 32 - Agentes de apoio pedagógico entrevistados na escola pública

Quadro 33 - Relacionamento interpessoal com professores escolas públicas

Quadro 34 - Relacionamento interpessoal com a direção - escolas públicas

Quadro 35 - Relacionamento interpessoal com a coordenação pedagógica - escolas públicas

Quadro 36 - Avaliação dos alunos pelos professores - escolas públicas

Quadro 37 - Relacionamento interpessoal com os professores escolas privadas

Quadro 38 - Relacionamento interpessoal com a direção - escolas privadas

Quadro 39 - Relacionamento interpessoal com a coordenação 
pedagógica - escolas privadas

Quadro 40 - Avaliação dos alunos pelos professores - escolas

privadas

84

Quadro 41 - Perfis dos pais entrevistados na escola privada .......... $\quad 96$

Quadro 42 - Perfil dos pais entrevistados na escola pública ........... $\quad 97$

Quadro 43 - Frequência de estudo em casa - pais escola privada . 105

Quadro 44 - Verifica as tarefas escolares - pais escola privada .... 108

Quadro 45 - Ajuda nas tarefas escolares - pais escola privada ..... 109

Quadro 46 - Frequência ao professor particular - pais escola privada

Quadro 47 - Frequência ao professor particular - alunos escola privada

Quadro 48 - Gosto pela Leitura - pais escola privada ................... 119

Quadro 49 - Frequência de estudo em casa - pais escola pública . 123

Quadro 50 - Gosto pela leitura - pais escola pública ..................... 126

Quadro 51 - Verifica as tarefas escolares - pais escola pública ..... 130

Quadro 52 - Ajuda nas tarefas escolares - pais escola pública ...... 130

Quadro 53 - Alunos entrevistados na escola privada .................... 153

Quadro 54 - Alunos entrevistados na escola pública ..................... 153

Quadro 55 - Atividades extraescolares na escola privada .............. 155

Quadro 56 - Atividades extraescolares na escola pública ............... 156 


\section{Lista de Gráficos}

Gráfico 1 - Nível socioeconômico das famílias 29

Gráfico 2 - Pais e alunos participantes do survey nas escolas $3 \quad 44$

Gráfico 3 - Pais e alunos participantes do survey nas escolas 7 